\title{
HUBUNGAN PENGETAHUAN DENGAN KECEMASAN IBU NIFAS DALAM MELAKUKAN MOBILISASI DINI
}

\author{
Rizka Innayatun Mubarokah ${ }^{1,2}$, Agus Nugroho², Septerina Purwandani² \\ 1, Universitas Sebelas Maret \\ 2, Politeknik Kesehatan Kementerian Kesehatan Semarang \\ *Email:Rizka.inn@gmail.com
}

\begin{abstract}
Abstrak
Periode post partum adalah saat paling kritis untutk mencegtah kematian ibu. Mobilisasi dini telah tetrbuktti bermanfaat untuk mengturangi timbulnya tromboemboli dan mempercepat pemulihan kekuatan ibu. Faktor emosionalt yang mempengaruhi mobiltisasi adalah kecemasan. Kecemasan juga dipengaruhi oleh perilaku seseorang. Ibu dengtan pengeahuatn memperltakukan dirinya sendiri dengan periltaku yang lebih baik sehingga dapat mengturangi morbiditas dan mortalittas ibtu. Tujuan penelitian untutk mengteahui hubingan antatra pengetahuan dengtan kecemasan pada ibu pasca meltahirkan. Jenis peneltiian ini adalah analitik observasional dengan pendekatan cross-sectional, dangt menggunakan analisis statistik range spearman. Teknik pemilihan responden menggunakan accidental sampling dengan jumlah 38 responden. Hasil penelitian menunjukkan karakteristik responden berdasarkan pengetahuan dengan pengetahuan baik $8(21,1 \%), 25(65,8 \%)$ pengeahuan sedang, dan $5(13,2 \%)$ pengetahuan kurang. Karaktertitstik esponden menurut kecemasan adalah $27(71,1 \%)$ idak memiliki pengalaman kecemasan, $8(21,1 \%)$ dengan kecemasan rendah, dan $3(7,9 \%)$ kecemasan sedang. Analisis rank spearman menunjukkan koefisien korelasi 0,415 dengan nilai signifikansi kurang dari 0,005 adalah 0,010. Penelitian ini signifikan dengan hubungan yang cukup kuat. Kesimpulan dari peneltian ini adalah sebagian besar ibu memiliki pengteahuan sedang, pengaltaman kecemasan rendah dan ada hubungan yang cukup kuatt antara pengetahtuan dan kecemasan saa melakukan mobilisasi dini pada ibu pasca melahirkan. Dianjurkan bagi ibu pasca bersalin untuk meningtkakant pengetahuan mereka tentang mobilisasi dini sejak masa kehamilan yaitu dengan menghadiri kelas ibu hamil secara teratur dan konseling prenatal dengan petugas kesehatan. Disisi lain tenaga medis diharapkan dapat meningtkatkan program konseling kesehatan tentang mobilisasi dini.
\end{abstract}

Kata kunci : pengetahtuan, kecemasan, mobiltisasi dini

\section{Abstract}

Postpartum period is the most critical moment to prevent maternal deaths. Early mobilization has proven beneficial to reduce the incidence of thromboembolism and accelerate the restoration of moms power. Emotional factors affecting early mobilization is anxiety. Anxiety also affected by the conduct of a person. Mother with higher knogledge treating herself with better behavior and it could reduce maternal morbidity and mortality. This research aims to find out the relationship between knowledge and the maternal postnatal anxiety. This type of researce is observational analytic with cross-sectional approach, and use rank spearman statistical analytic. Respondent selection technique using accidental sampling with total38 respondents. The result showed the characteristics of respondents by knowledge with good knowledge $8(21,1 \%), 25(65,8 \%)$ moderate knowledge, and $5(13,2 \%)$ less knowledge. The characteristics of respondents by anxiety are $27(71,1 \%)$ have no experience of anxiety, $8(21,1 \%)$ with low anxiety, and $3(7,9 \%)$ moderate anxiety. Spearman rank analysis showed a correlation coefficient of 0,415 with significant value less than 0,005 is 0,010 . This research is significance with strong enough relationship. The conclution of this study were most of maternal potnatal have moderate knowledge, low anxiety experience and there was a fairly strong relationship between knowledge and anxiety while doing early mobilization in maternal postnatal. It is recomended for maternal postnatal to escalute their knowledge about the early mobilization by attending pregnant women class regularlyand prenatalcounseling. In the other hand the medical personels are expectedto increase health counceling program about early mobilization.

Keywords : knowledge, anxiety, early mobilization 


\section{Pendahuluan}

Menurunkan angka kematian ibu merupakan salah satu target dari SDG's. Saat ini Angka Kematian Ibu (AKI) masih tinggi diangka 305/100000 kelahiran hidup jauh dari harapan sebanyak 102/100000 kelahiran hidup (Kemenkes, 2018). Selama postpartum terjadi sekitar $61 \%$ kematian ibu (Creanga, et $a l ., 2015)$. Penyebab kematian ibu antara lain karena komplikasi anastesi, embolism (air, cairan amnion dan trombus), dan peripartum kardiomiopati (Tessema, et al. 2017).

Thromboemboli/thrombosis vena merupakan terbentuknya thrombus di vena yang terletak di pelvis dan mengalami dilatasi (Bahiyatun, 2009). Apabila thrombosis vena tidak segera diatasi dapat berkembang menjadi embolus paru dan akan membahayakan ibu (Quinlan \& Murphy, 2015). Mobilisasi dini terbukti sebagai evidence base yang baru dalam penanganan thrombosis / thrombo emboli (Liu, et al., 2015). Apabila ibu malas melakukan mobilisasi dini karena lelah dan sakit, maka ibu akan terancam mengalami thrombosis vena (Bahiyatun, 2009). Mobilisasi dini juga sangat penting dilakukan pada masa nifas karena dapat mempercepatproses involusi uterus (Nara, et al., 2013).

\footnotetext{
Terdapat beberapa faktor yang mempengaruhi mobilisasi, yaitu faktor
}

fisiologis, faktor emosional dan faktor perkembangan. Faktor emosional yang mempengaruhi mobilisasi adalah kecemasan (anxiety) (Potter \& Perry, 2010). Kecemasan merupakan antisipasi terhadap ancaman yang mungkin terjadi, dan merupakan respon emosional atas ancaman yang dirasakan (Crocq, 2015). Kecemasan seringkali ditandai dengan mudah marah, cemas, mudah gugup, perasaan tegang kewaspadaan berlebih dan kadang menyebabkan keringat di telapak tangan (Anisa \& Ifdil, 2016). Kecemasan dapat meningkatkan detak jantung, mengaktifkan system neuroendokrin, tekanan darah dan eksitasi jantung, dan ketidak seimbangan elektrolit (Sahin, et al., 2016).

Kecemasan dipengaruhi oleh perilaku seseorang, intensitas perilaku meningkat sejalan dengan anxietas (Stuart, 2013). Faktor pendukung perilaku salah satunya adalah pengetahuan (Notoatmojo, 2012). Pengetahuan ibu tentang masa nifas dapat mempengaruhi perilakunya dalam menghadapi masa nifas (Bahiyatun, 2009).

Pengetahuan merupakan segala pengalaman yang didapatkan oleh manusia, hasil mengingat suatu hal, termasuk mengingat kembali sesuatu yang pernah dialami baik sengaja ataupun tidak (Mubarak, 2012). Semakin tinggi pengetahuan maka semakin baik perilakunya 
dalam merawat dirinya sehingga dapat mengurangi angka kesakitan dan kematian maternal (Bahiyatun, 2009).

\section{Metodologi penelitian}

Jenis penelitian ini merupakan penelitian observasional analitik dengan pendekatan cross sectional. Sampel dalam penelitian ini adalah seluruh ibu melahirkan di sebuah rumah saki di kota Purbalingga Kab. Purbalingga yang memenuhi kriteria inklusi dan eksklusi yaitu 38 pasien. Kriteria inklusi pada penelitian ini yaitu: ibu bersalin dengan persalinan pervagina, ibu primipara, ibu dalam masa nifas, bersedia menjadi responden dan bias membaca dan menulis. Kriteria eksklusi dalam penelitian ini adalah ibu nifas yang tidak berada ditempat ketika pengkajian dilakukan dan ibu dengan gangguan jiwa. Teknik pengambilan sampel dilakkan dengan accidental sampling. Uji statistik yang digunakan analisis bivariate dengan uji spearman rank.

\section{Hasil Penelitian}

Distribusi responden berdasarkan pengetahuan ibu nifas disajikan pada gambar 1

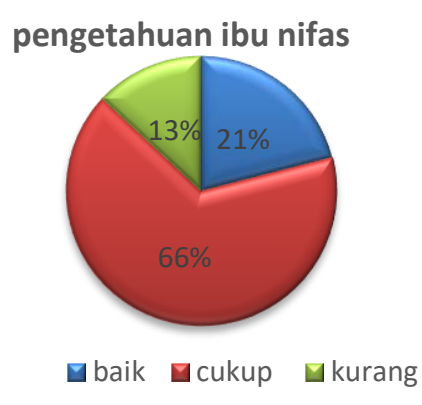

\section{Gambar 1. Distribusi pengetahuan ibu nifas}

Pengetahuan ibu nifas terdiri dari tiga kategori, responden yang memiliki pengetahuan baik sebanyak8 orang ibu nifas $(21,1 \%)$, sedangkan responden yang mempunyai pengetahuan cukup memiliki jumlah yang palingbesar yaitu 25 responden $(65,8 \%)$, sisanya 5 orang responden $(13,2 \%)$ mempunyai pengetahuan kurang.

Distribusi responden berdasarkan kecemasan ibu nifas disajikan pada gambar 2

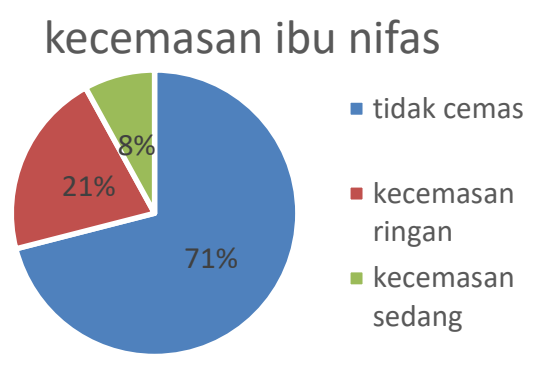

\section{Gambar 2. Distribusi kecemasan pada ibu nifas}

Berdasarkan gambar diagram 2 datam peneltiian mengenai hubungan pengetahuan detngan kecemasan ibu nifas dalam melakukan mobilisasi dini, dari total 38 responden terdapat 27 responden atau $71,1 \%$ 
tidak mengalami kecemasan. 8 responden atau $21,1 \%$ mengalami kecemasan riongan dan 3 orang responden atau 7,9\% mengalami kecemasan sedang.

Hasil untuk analisis dalam penelitian ini diltakukan dengan menggunakan uji spearman rank mengenai hubungan pengetahuan dengan kecemasan ibu nifas dalam melakukan mobilisasi dini dapat dilihat pada tabel 1 berikut.

Tabel 4.1 Hasil analisa data hubungan antara pengetahuan dengan kecemasan ibu nifas dalam melakukan mobilisasi dini

\begin{tabular}{|c|c|c|c|c|c|c|c|c|c|c|}
\hline \multirow[t]{3}{*}{ Pengetahuan } & \multicolumn{6}{|c|}{ Kecemasan } & \multirow{2}{*}{\multicolumn{2}{|c|}{ Total }} & \multirow[t]{3}{*}{ c } & \multirow[t]{3}{*}{$\mathbf{P}$} \\
\hline & \multicolumn{2}{|c|}{ Tidak cemas } & \multicolumn{2}{|c|}{ ringan } & \multicolumn{2}{|c|}{ Sedang } & & & & \\
\hline & $f$ & $\%$ & $\mathrm{f}$ & $\%$ & $\mathrm{f}$ & $\%$ & $\mathrm{f}$ & $\%$ & & \\
\hline Baik & 8 & 100 & 0 & 0 & 0 & 0 & 8 & 100 & 0,415 & 0,001 \\
\hline Cukup & 17 & 68 & 7 & 28 & 1 & 4 & 25 & 100 & & \\
\hline \multirow[t]{2}{*}{ Kurang } & 2 & 50 & 1 & 20 & 2 & 40 & 5 & 100 & & \\
\hline & 27 & 71,05 & 8 & 21,05 & 3 & 7,89 & 38 & 100 & & \\
\hline
\end{tabular}

Berdasarkan hasil uji statistik analisa korelasi menggunakan rank spearman antara pengetahuan dengan kecemasan ibu nifas menunjukkan nilai koefisien korelasi 0,415 dengan nilai kemaknaan $(p)$ lebih kecil dari 0,05 yaitu 0,010. Hasil analisis tersebut menunjukkan ada hubungan pengetahuan dengan kecemasan ibu nifas dalam melakukan mobilisasi dini.

\section{Pembahasan}

Responden dalam penelitian ini paling banyak memiliki pengetahuan cukup yaitu 25 responden $(65,8 \%)$. Menurut Bahiyatun (2009) pengetahuan merupakan salah satu faktor untuk mencapai derajat kesehatan masyarakat yang optimal. Sedangkan menurut Notoatmojo (2012), pengteahuan juga dapatt mempengaruhi morbiditas dan mortalitas. Perilaku yag didasari olteh pengeahuan akan lebih langgeng daripada perilaku yag tidak didasari oleh pengetahuan.

Pengetahuan mengenai perawatan masa nifas melputi pengetahuan tentang perawatan genitalia, istirahat, gizi, latihan dan juga perawatan payudara yang memiliki 
tujuan untuk membantu memulihkan kesehatan ibu, mempertahankan kesehatan psikologis, mencegah infeksi dan komplikasi serta mempertlatncar pembentukan Air Susu Ibu (ASI) (Bahiyatun, 2009).

Hal ini serupa dengan penelitian yang dilaukan oleh Buhari dkk (2015), dengan judul hubungan tingkat pengetahuan denga mobilisasi dini pada ibu nifas di puskesmas likupang timur kecamatan likupang timur. Dari hasil peneltian tersebut didapatkan kesimpulan bahwa semakin tinggi tingkat pengetahuan dan pengalaman yang didapat ibu maka semakin akan melakukan mobilisasi dini sesuai tahap-tahap mobilisasi dini.

Persentase kecemasan yang dialami reponden dalam penelitian ini sebanyak 11 responden $(28,9 \%)$ sedangkan sisanya tidak mengalami kecemasan. Hastuti (2015), menyatakan bahwa kecemasan dapat ditandai dengan adanya emosi yang tidak stabil, sangat mudah terganggu dan kemarahan, sering berada dalam keadaan exited atau gemetaran dan juga gelisah.

Sebuah penelitian juga menunjukkan bahwa kecemasan pada kehamilan terkait dengan peningkatan pada biomarker stress, seperti corticotrophin-releasing hormone dan kortisol (Field, 2017). Stressor pencetus kecemasan dapat berasal dari sumber internal maupun eksternal Annisa dan Ifdil (2016). Kecemasan pada umumnya adalah manifestasi dari stress (Hawari, 2011).

Ibu yang memiliki pengetahuan dan pemahaman baik tenangt mobilisasi dini akan lebih memiliki kesiapan yang lebih baik dalam menghadapi mobiltisasi dini, edangkan pengetahuan kurang akan cenderung lebih mengalami perasaan cemas dalam melakukan mobilisasi dini. hal ini karena mereka lebih dapat berpikir positif dengan menganggap dan mengatasi persoalannya secara lebih optimis dan mengarahkan pikirannya kedepan.

Harapan yang positif akan membantu efektifitas seseorang dalam memberikan respons yang positif terhadap suatu tekanan, artinya wanita lebih mampu melihat kesulitan dengan pandangan yang lebih luas dan mampu mempunyai semangat yang lebih besar untuk menghadapi kesulitan-kesulitan semaksimal mungkin terutama pada wanita yang harus melakukan mobilisasi dini.

Pada wanita yang belum mengerti tentang mobilisasi dini serta informasi yang didapat kurang mengenai mobilisasi dini, mereka akan menganggap mobilisasi dini sebagai sesuatu yang harus ditutupi atau dihindari 


\section{Kesimpulan}

Sebagian besar responden dalam penelitian ini memiliki pengetahuan cukup mengenai mobilisasi dini yaitu sebanyak 25 responden $(65,8 \%)$.

Sebanyak 11 responden $(28,9 \%)$ dari total 38 responden dalam penelitian ini mengalami kecemasan dalam melakukan mobilisasi dini dimana sebagian besar 8 $(21,15 \%)$ responden mengalami kecemasan ringan sedangkan $27 \quad(71,1 \%) \quad$ tidak mengalami kecemasan dalam melakukan mobilisasi dini

Terdapat hubungan cukup kuat antara pengetahua dengan kecemasan ibu nifas dalam melakukan mobilisasi dini. Nilai $p$ value $=0,010(p$ value $<0,05)$ dan nilai koefisien korelasi 0,415 .

Sebagian besar ibu memiliki pengetahuan sedang, pengalaman kecemasan rendah dan ada hubungan yang cukup kuatt antara pengetahtuan dan kecemasan saa melakukan mobilisasi dini pada ibu pasca melahirkan. Dianjurkan bagi ibu pasca bersalin untuk meningkatkan pengetahuan mereka tentang mobilisasi dini sejak masa kehamilan yaitu dengan menghadiri kelas ibu hamil secara teratur dan konseling prenatal dengan petugas kesehatan. Disisi lain tenaga medis diharapkan dapat meningkatkan program konseling kesehatan tentang mobilisasi dini.

\section{Referensi}

Annisa, D. F \& Ifdil. (2016). Konsep Kecemasan (Anxiety) pada Lanjut Usia (Lansia). Konselor. 5(2).pp 93-99

Bahiyatun. Buku ajar asuhan kebidanan nifas normal. Jakarta: EGC

Buhari I. S. , Esther H., Rina Kundre. (2015). Hubungan tingkat pengetahuan dengan mobilisasi dini pada ibu nifas di puskesmas likupang timur kecamatan likupang timur . ejournal keperawatan $e-K p$. Vol 3 (1).

Creanga, A. A, Berg, C. J., Syverson, C., Seed, K., Bruce, F. C., \& Callaghan, . M. (2015). Pregnancy-related mortality in the United States, 2000620101. Obstetric \& Gynecology, 125(1), 5-12. doi:https://doi.org/10.1097/AOG.000 $\underline{0000000000564}$

Crocq, M. (2015). A History of anxiety: from Hipocrates to DSM. Clinical research, Dialogues in Clinical Neuroscience - Vol 17 .No. 3, 319325.

https://www.ncbi.nlm.nih.gov/pubme $\mathrm{d} / 26487812$ 
Field, Tiffany. (2017). Infant Behavior and Development Prenatal anxiety A review, 49(March), 120-128. https://doi.org/10.1016/j.infbeh.2017.0 $\underline{8.008}$

Hastuti, Dwi. (2015). Hubungan pengetahuan tentang sectio caesarea dengan kecemasan ibu pre operasi di ruang catleya RS Panti Waluyo Surakarta. Surakarta: Stikes Kusuma Husada Surakata.

Hawari D. (2011). Manajemen Cemas dan Depresi. Jakarta: Balai penerbit Fakultas kedokteran Universitas Indonesia.

Kemenkes RI. (2018). Profil Kesehatan Indonesia Tahun 2017. Pusat data dan informasi Kementrian Kesehatan RI: Jakarta

Liu, Z., Tao, X., Chen, Y., Fan, Z., \& Li, Y. (2015). Bed rest versus early ambulation with standard anticoagulation in the management of deep vein thrombosis: a metaanalysis. PloS one, 10(4), e0121388. doi:

https://doi.org/10.1371/journal.pone. $\underline{0121388}$

Mubarak, Wahid I. (2012). Promosi Kesehatan Masyarakat Konsep dan
Aplokasi dalam Kebidanan. Jakarta: Salemba Medika

Nara, P., Ari A \& Eti S. (2013). Gambaran tingkat pengetahuan ibu nifas tentang senam nifas di BPM Raji Aminah Pojoksari Kecamatan Ambarawa Kabupaten Semarang. Karya Tulis Ilmiah. Surakarta : Perpustakaan UNS

Notoatmojo, S. (2012). Promosi kesehatan dan ilmu perilaku: Jakarta: Rineka Cipta

Potter, P. A \&Perry, A. G. (2010). Buku Ajar Fundamental Keperawatan. Edisi ketujuh, buku ketiga. Jakarta: EGC.

Quinlan, J. D., Murphy, N. J. (2015). Cesarean Delivery: Counseling Issues and Complication Management. American Family Physician. Volume 92 (3), 178-185

https://www.ncbi.nlm.nih.gov/pubmed/ $\underline{25822271}$

Sahin, Tuna, Ersel G., Sarac, M., \& Sibel T. (2016). Association between preoperative maternal anxiety and neonatal outcomes: a prospective. Journal of Clinical Anesthesia, 33, 123126.

https://doi.org/10.1016/j.jclinane.2016. $\underline{03.022}$

Stuart, Gail W. (2013). Prinsip dan praktik keperaatan kesehatan jiwa. Jakarta: Elsevier.

Tessema, G. A., Caroline, O, L., Yohannes, A. M., Awoke, M., Sintayehu, A. H., 
Rizka Innayatun Mubarokah, Agus Nugroho, Septerina Purwandani. Hubungan Pengetahuan Dengan Kecemasan Ibu Nifas Dalam Melakukan Mobilisasi Dini

Abiye. H. (2017). Trends and causes of maternal mortality in ethiopia during 1990-2013: findings from the global burden of diseases study 2013. BMC Public Health.. 17:160. Doi: https://doi.org/10.1186/s12889-017$\underline{4071-8}$ 